\title{
Anatomical Variations of Brachial Plexus in Fetal Cadavers
}

\author{
Alparslan KIRIK'1, Senem Ertugrul MUT², Mehmet Kadri DANEYEMEZ ${ }^{3}$, Halil Ibrahim SECER ${ }^{4}$ \\ ${ }^{1}$ Etimesgut Sehit Sait Erturk State Hospital, Neurosurgery Clinic, Ankara, Turkey \\ 2University of Kyrenia, Faculty of Medicine, Visiting Professor, Near East University, Faculty of Medicine, Department of Neurology, \\ Girne, Turkish Republic of Northern Cyprus \\ ${ }^{3}$ University of Health Sciences, Gulhane Training and Research Hospital, Department of Neurosurgery, Ankara, Turkey \\ ${ }^{4}$ University of Kyrenia, Faculty of Medicine, Visiting Professor, Near East University, Faculty of Medicine, Department of Neurosurgery, \\ Girne, Turkish Republic of Northern Cyprus \\ This study has been presented as an oral presentation at the $25^{\text {th }}$ Scientific Congress of the Turkish Neurosurgical Society between 22 and \\ 26 April 2011 at Antalya, Turkey.
}

\section{ABSTRACT}

AIM: To demonstrate the anatomical variations of the infantile brachial plexus.

MATERIAL and METHODS: A total of 20 plexus brachialis from 11 fetal cadavers were dissected and examined microscopically. The branching patterns and variations were evaluated. The width of the nerves was assessed at the level of the nerve root, trunk and cord on the basis of all brachial plexuses and they were arranged in terms of thickness.

RESULTS: Half of the brachial plexuses were found to be prefıxed, while $15 \%$ were found to be postfixed. Truncus superior, medial cord and nervus ulnaris were found in normal formation, whereas anatomical variations were detected in the rest of the structures. The plexus brachialis elements were arranged in the following order from large to small according to their average thicknesses: C7>C6>C8>C5=T1; TS>Tl >TM; PC >LC>MC.

CONCLUSION: Since the risk of injury for variated branches is higher, understanding the anatomical variations of plexus brachialis and its extensions are of significant importance during surgical intervention.

KEYWORDS: Anatomical variation, Brachial plexus, Fetus

ABBREVIATIONS: BP: Brachial plexus, C: Cervical root, T: Thoracic root, TS: Truncus superior, TSdp: Division posterior of truncus superior; TM: Truncus medius, TMda: Division anterior of truncus medius, TMdp: Division posterior of truncus medius, TI: Truncus inferior, TIdp: Division posterior of truncus inferior, LC: Lateral cord, MC: Medial cord, PC: Posterior cord, Cl: Clavicula, SC: Musculus subclavius, SCM: Musculus sternocleidomastoideus, SA: Musculus serratus anterior, PMj: Musculus pectoralis major, PMn: Musculus pectoralis minor, GT: Glandula troidea, Tr: Trachea, AA: Arteria axillaris, VA: Vena axillaris, A: Nervus axillaris, M: Nervus medianus, U: Nervus ulnaris, MCT: Nervus musculocutaneus, R: Nervus radialis, CBM: Nervus cutaneus brachi medialis, DS: Nervus dorsalis scapula, SS: Nervus suprascapularis, SSS: Nervus subscapularis superior, SSI: Nervus subscapularis inferior, TD: Nervus thoracodorsalis, CABM: Nervus cutaneus antebrachi medialis, PL: Nervus pectoralis lateralis, PM: Nervus pectoralis medialis, TL: Nervus thoracicus longus, P: Phrenic nerve. 


\section{INTRODUCTION}

$\mathrm{T}$ The brachial plexus (BP) is an important structure due to its anatomical location and its vulnerability to damage. There are several variations in the formation and branching pattern. Therefore, knowledge of the anatomy and variations of $\mathrm{BP}$ is important in reducing the neurological damage that can be caused by surgical intervention $(1,6)$.

$\mathrm{BP}$ is mostly formed by the anterior rami of C5-C8 and T1 spinal nerves and bifurcates into the upper $(\mathrm{C} 5, \mathrm{C} 6$ spinal nerves), middle and lower trunks ( $\mathrm{C} 7$ and the union of $\mathrm{C} 8$, T1 spinal nerves). After the formation of trunks, the anterior and posterior divisions continue and they lead to the lateral cord, medial cord and posterior cord. After integration of the two anterior divisions of the upper truncus and middle truncus, the lateral cord is formed. The anterior division of the lower truncus continues as the medial cord. The fusion of the posterior divisions of the three trunks forms the posterior cord. Later, the cords give off terminal nerve branches that supply the upper extremities (7).

It has been demonstrated in studies that extensive variations may accompany BP in the formation of roots, trunks, divisions and cords. For instance, a C4 nerve supernumerary root was found or the T2 nerve root formed the BP (27). Studies conducted by Singhal et al., Matejcik, and Fazan et al., reported an incidence of prefixed BP at a proportion of $24 \%$, $21.7 \%$ and $48 \%$, respectively $(4,14,23)$. On the other hand, postfixed BPs were reported by Singhal et al. and Matejcik et al. with a frequency of $5 \%$ and $2 \%$, respectively $(14,23)$. In general, variations are not limited to the origin of the BP, although division, cord and distal ramification anomalies have been also reported (27).

There are few research studies that have investigated fetal brachial plexuses. Studies by Uysal et al. and Uzmansel et al. have conducted morphological examinations of BP in the fetal period $(24,25)$. Due to the limited number of investigations, the aim of this study was to present BP variations in fetal cadavers.

\section{MATERIAL and METHODS}

The study was performed at the microsurgery laboratory of the Neurosurgery Department of Gulhane Military Medical Academy with the approval of the Ankara $7^{\text {th }}$ Ethical Committee (dated 13.01.2010, with decision number 22). All of the material used in the study belonged to the pathology department. A Zeiss Universal S3 operation microscope and a Sony W-290 digital camera were used. This anatomical study was conducted to assess the anatomical variations of the brachial plexus formation in 20 BPs from 11 fetuses sent for pathologic investigation from the gynecology and obstetrics clinic to the pathology laboratory at Gulhane Military Medical Academy Hospital. All the materials were aborted due to intrauterine death. Bilateral brachial plexus dissection was performed on 9 of the fetal cadavers. In 2 fetal cadavers, the anatomical structure of the left brachial plexus had been damaged before the study, which meant that only the right brachial plexuses were dissected. Fetuses were 23-32 (mean
28) weeks old and weighed between 460 and 1,470 (mean 923,64) grams (Table I).

The operating microscope was used in all dissections. The same incision that was described by MacCarty, Dunkerton, Hentz, Laurent and Ochiani was used before visualization of the brachial plexus and the branches in the plexus brachialis surgery $(3,8,10,12,18)$. The skin incision was performed in three steps for dissection. The initial incision was made starting from the mastoid overhang through the lateral side of the sternocleidomastoid muscle, ending at the medial aspect of the clavicle. The second skin incision began at the end of the first incision, through the superior clavicle line, at which point the incision was oriented below to fit to the deltopectoral sulcus and was extended to the midpoint of the inner side of the arm. The third incision was made from the deltopectoral sulcus to the axillary fossa (Figure 1). The skin flap, fascia cervicalis superficialis, fascia cervicalis profunda and platysma muscle were all removed. The sternocleidomastoid muscle was cut at the insertion point of the clavicula and sternum. After removal of the sternocleidomastoid and omohyoid muscles, the clavicula was taken out by cutting the nearby articulatio acromioclavicularis and articulatio sternoclavicularis. Additionally, the pectoralis major and pectoralis minor muscles were removed by cutting close to their insertion points in order to visualize the divisions of the BP in the infraclavicular fossa. The anterior and median scalene muscles and all the tissues positioned in front of the C4-T2 vertebra levels were excised for the purpose of visualizing the nerve roots that composed the BP. The axillary subclavian artery and vein as well as all their branches were removed. During the dissection, the right and left BP, their branches, as well as their variations, were evaluated.

Furthermore, the thickness of the ramus ventralis nervi spinalis, trunks and cords were measured in millimeters. The thickness of the ramus ventralis nervi spinalis was measured

Table I: Gender, Gestational Age and Weight of Fetuses

\begin{tabular}{cccc}
\hline Fetus No & Gender & $\begin{array}{c}\text { Gestational age } \\
\text { (weeks) }\end{array}$ & $\begin{array}{c}\text { Weight } \\
\text { (gram) }\end{array}$ \\
\hline 1 & M & 28 & 910 \\
\hline 2 & M & 26 & 820 \\
\hline 3 & F & 27 & 850 \\
\hline 4 & M & 30 & 1220 \\
\hline 5 & F & 30 & 1180 \\
\hline 6 & F & 30 & 1140 \\
\hline 7 & F & 32 & 1470 \\
\hline 8 & M & 24 & 550 \\
\hline 9 & M & 23 & 460 \\
\hline 10 & F & 26 & 760 \\
\hline 11 & M & 28 & 800 \\
\hline
\end{tabular}

M: Male, F: Female. 
from the intervertebral foramen exit point. The thicknesses of the other neural structures were measured at the level of their formation.

\section{RESULTS}

In the present study, a total of 20 plexuses from 6 male and 5 female fetal cadavers were examined. All BPs were located between the scalene anterior and scalene medius muscles and were united to form a truncus. BP was found to be prefixed in $10 \mathrm{BPs}$ (Figure 1A), while there was no C4 involvement in the others. Among the BPs, $15 \%$ were found as postfixed plexus. In all of these postfixed BP cases, prefixed BP was also observed (Figure 1A).

\section{Trunk Anomalies}

In $10 \mathrm{BPs}, \mathrm{C} 4, \mathrm{C} 5$ and $\mathrm{C} 6$ roots formed the truncus superior (TS), while in the remaining $10 \mathrm{BPs}$, the $\mathrm{C} 5$ and $\mathrm{C} 6$ roots formed the TS. The truncus medius (TM) consisted of the $\mathrm{C} 7$ root and no variations were found in any of the BPs. In 17 cases $(85 \%)$, the $\mathrm{C} 8$ and $\mathrm{T} 1$ roots formed the truncus inferior (TI), while in $3(15 \%)$ cases, the C8, T1 and T2 roots formed the TI.

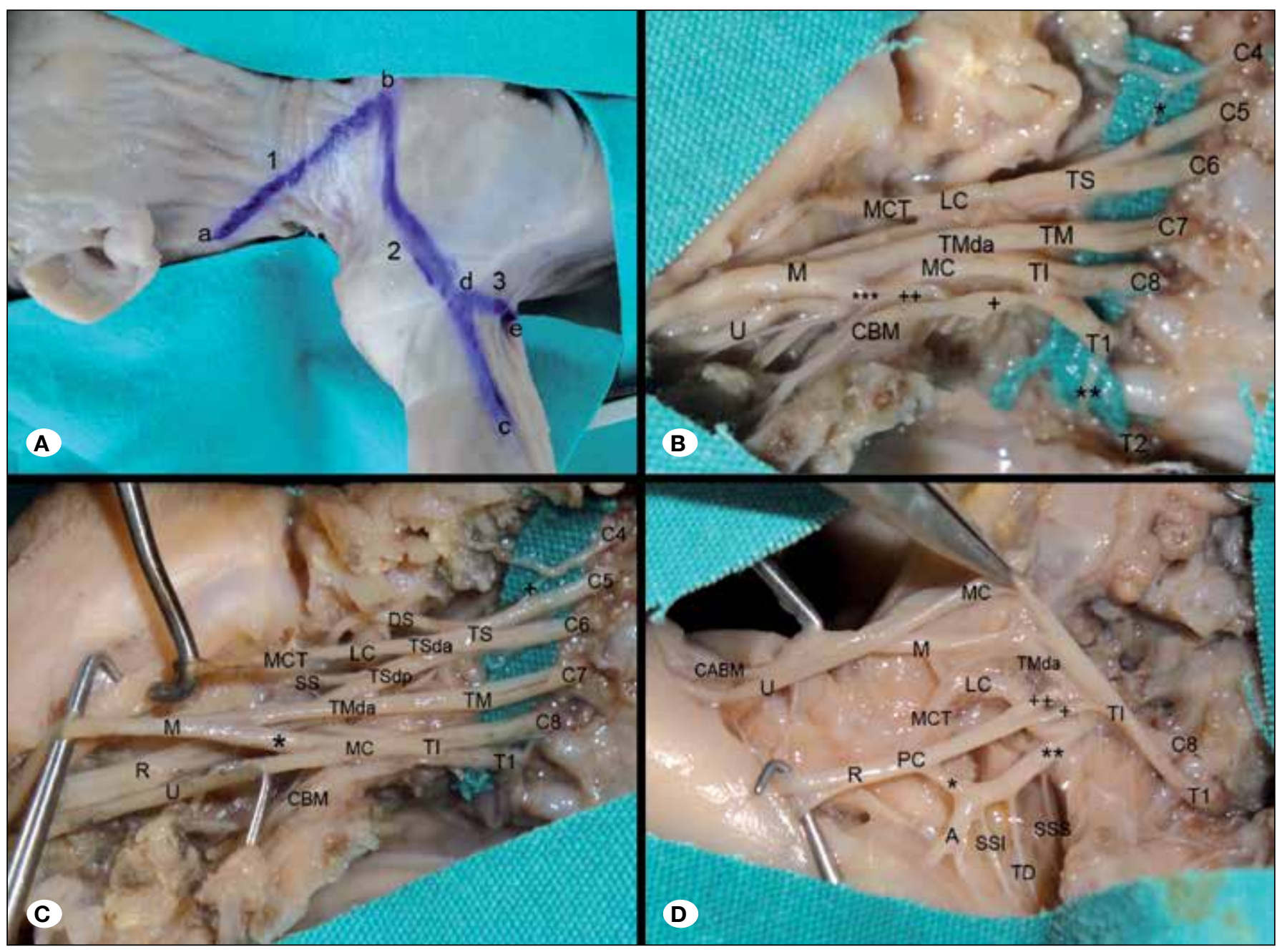

Figure 1: A) This figure shows three incisions of skin for dissection. The initial incision is between points a and $b$ through the first line. The second incision is between points $b$ and $c$ through the second line. The last incision is between points $d$ and e through the third line. B) Right BP: a branch from the C4 spinal nerve $\left(^{*}\right)$ joins the C5 spinal nerve (prefixed plexus). A branch of the T2 spinal nerve $\left(^{\star \star}\right)$ joins the T1 spinal nerve (postfixed plexus). The nervus medianus consists of the anterior division of the truncus medius and radix medialis nervi mediani $\left.{ }^{(* \star}\right)$. A branch of the T1 spinal nerve (+) separates into two parts; one part is the nervus cutaneus brachi medialis and the other part is the nervus cutaneus antebrachi medialis (++). C) The lateral cord originates only from the anterior division of the truncus superior. The nervus medianus consists of the anterior division of the truncus medius and radix medianus nervi median, which is a branch of the medial cord $\left({ }^{*}\right)$. The nervus suprascapularis originates from the posterior division of the truncus medius. D) Right BP: the medial cord is removed and lifted with a tool. The nervus subscapularis superior, nervus subscapularis inferior and nervus thoracodorsalis originate from the posterior division of the truncus superior $\left(^{\star \star}\right)$. The posterior cord arises from posterior division of the truncus medius $(++)$ and the truncus inferior $(+)$, and an additional branch of the posterior division of the truncus superior $\left(^{\star}\right)$. Nervus axillaris separates two parts. 


\section{Cord Anomalies}

In 13 BPs (65\%) lateral cords (LC) were found in the normal anatomical structure. In 7 BPs (35\%), LCs were formed only by the TS (Figures 1, 2, 3, 4). In one of these 7 BPs (5\%), the anterior division of the TM gave off a small branch to the LC. Medial cords (MC) in all BPs and posterior cords (PC) in 18 BPs $(90 \%)$ were found in the normal anatomical structure. In 2 BPs (10\%), variations were observed. In one of these, the posterior divisions of the TM and TI first formed the PC, and the posterior division of the TS joined with the PC after giving the nervus subscapularis superior and inferior (Figure 2). In the other BP, the posterior division of the TS first gave off the nervus thoracodorsalis, then formed the PC with the posterior divisions of the TM and TI (Figure 1).

\section{Distal Ramification Anomalies}

In all BPs, the nervus musculocutaneous originated from the LCs. In only one BP (5\%), the musculocutaneous nerve received a communicating branch from the anterior division of the TM (Figure 3).

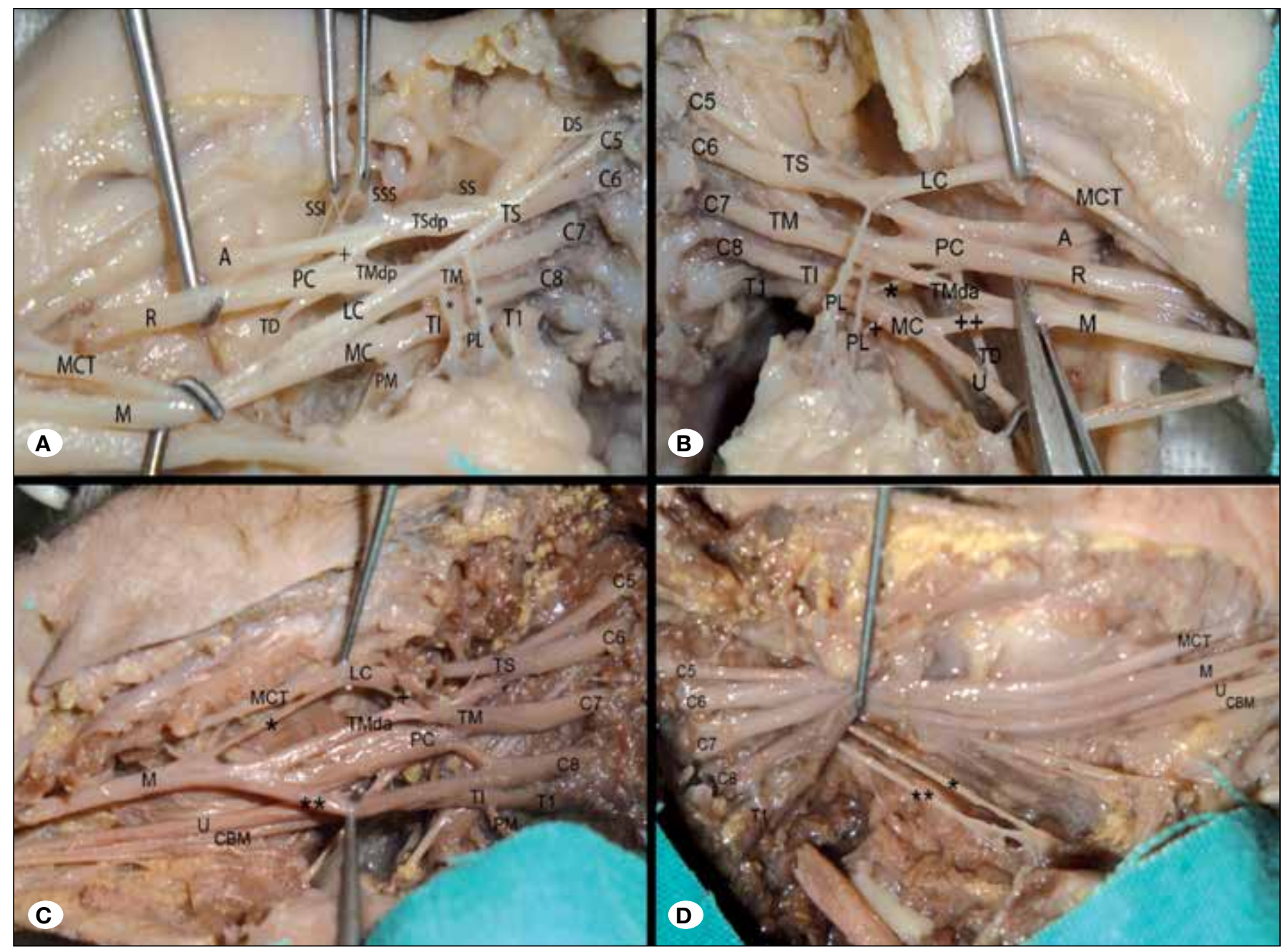

Figure 2: A) Right BP: the lateral cord and the medial cord are removed with a tool. The nervus axillaris, subscapularis superior and subscapularis inferior originate only from the posterior division of the truncus medialis. The nervus radialis and thoracodorsalis originate from the posterior cord. An additional branch of the posterior division of the truncus superior joins the posterior cord (+). The nervus pectoralis lateralis consists of two roots which arise from the anterior division of the truncus superior and truncus medius ( $\left.{ }^{*}\right)$. B) Left BP: there is a thin additional connection from the truncus inferior to the nervus radialis $\left(^{*}\right)$. The lateral cord originates only from the anterior division of the truncus superior. There are two pectoralis lateralis nerves, one of which arises from the anterior division of the truncus superior, and the other arises from the anterior division of the truncus medius. These nerves form a conjunction together. The nervus medianus consists of the radix medialis nervi mediani $(++)$ and the anterior division of the truncus medius. (+): nervus pectoralis medialis. C) Right BP: a thin branch of the anterior division of the truncus medius (+) joins the lateral cord. The median nerve consists of the radix lateralis nervi mediani $\left(^{*}\right)$, radix medialis nervi mediani $\left(^{* *}\right)$ and the anterior division of the truncus medius as an additional branch. The nervus pectoralis medialis originates from the T1 root. D) Left BP: there are two thoracicus longus nerves in the BP. One of them, which is marked with a star $\left(^{\star}\right)$, originates from the C5 root, while the other nerve, which is marked with two stars $\left({ }^{* *}\right)$ originates from the C6 and $\mathrm{C} 7$ roots. 
No anatomical variations were detected at the nervus ulnaris.

Nervus radialis variations were observed in 3 (15\%) BPs. This nerve received a thin branch from the anterior division of the TM in one BP (Figure 4), from the MC in the second and from the $\mathrm{Tl}$ in the third (Figure 2).

In 8 BPs (40\%), the nervus medianus was found to be normal, while in 12 BPs $(60 \%)$, variation was detected. It was observed that the nervus medianus was formed from the anterior division of the TM and MC in two BPs. In 10 BPs
(50\%), the radix lateralis nervi mediani, radix medialis nervi mediani, and one or more branches from the anterior division of TM were involved in the formation of the nervus medianus, which indicates that it was formed from 3 main roots (Figures $2,3)$. In 3 of the 10 BPS, it was observed that the branch from the anterior division of TM merged with the radix medialis nervi mediani in one BP (Figure 2), with radix lateralis nervi mediani in the second (Figure 3), and directly joined the nervus medianus in the third (Figure 2). In 1 of the $10 \mathrm{BPs}$, the anterior division of TM gave off four branches; one of them joined the

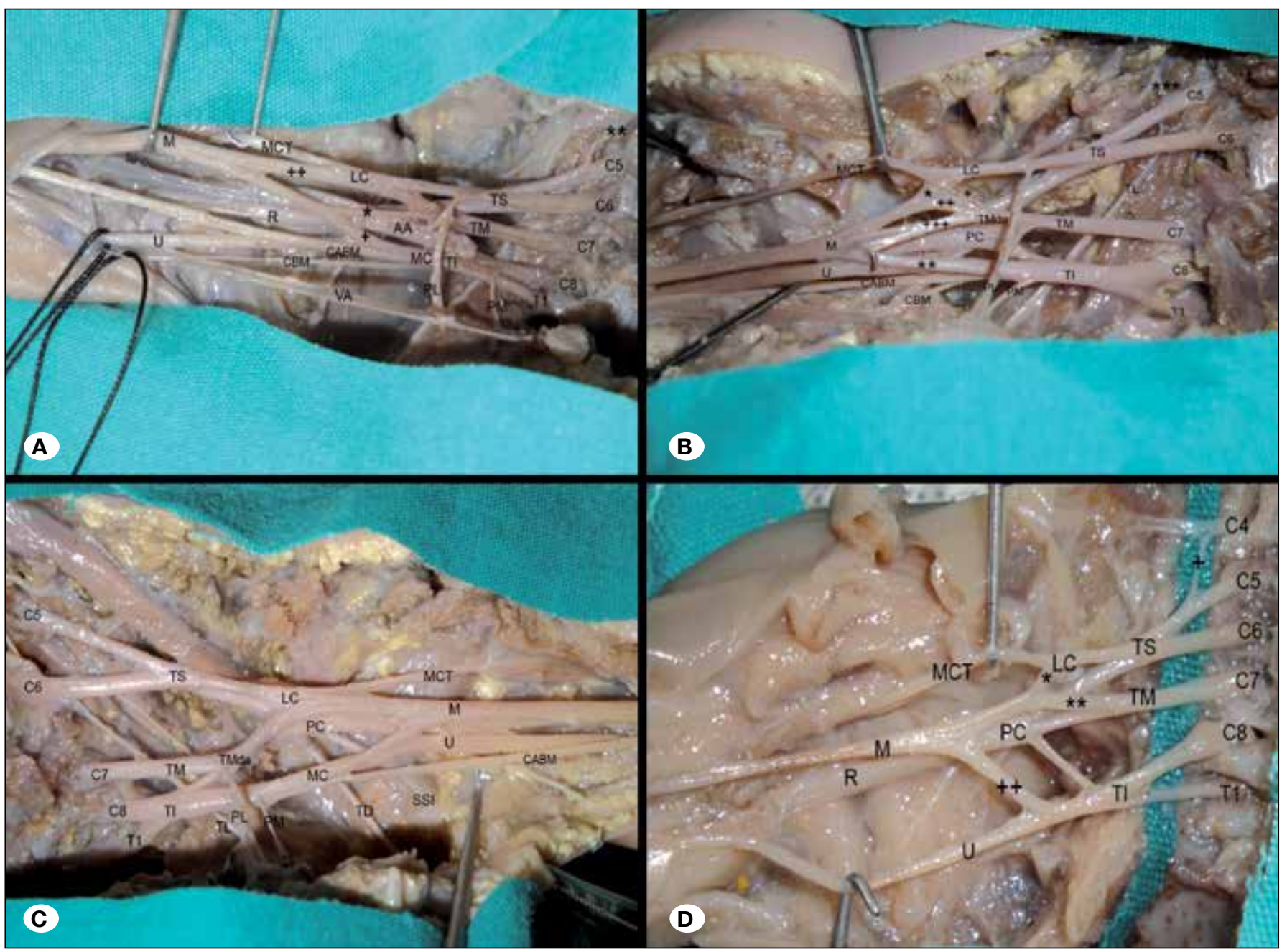

Figure 3: A) Right BP: A branch of the anterior division of the truncus medius $\left(^{*}\right)$ joins the nervus medianus as a third root. First, the branch joins the radix medialis nervi mediani $(+)$, then, this conjunction contributes to the median nerve with the radix lateralis nervi mediani $(++)$. The nervus pectoralis medialis originates from the T1 root. The nervus pectoralis lateralis originates from the anterior division of the truncus superior and the truncus medius as a conjunction of those branches. B) Right BP: The lateral cord originates only from the anterior division of the truncus superior. There is an additional connection (+) from the anterior division of the truncus medius to the nervus musculocutaneus. The median nerve consists of five roots. Two of the branches (++ and +++) contribute to the nervus medianus together with the radix lateralis $\left(^{*}\right)$ and the medialis $\left(^{* *}\right)$ nervi mediani. The nervus thoracicus longus arises from roots C5 and C6. But, there is no contribution to the nerve from the C7 root. C) Right BP: the nervus pectoralis lateralis arises only from the anterior division of the truncus medius. The nervus pectoralis medialis arises from the anterior division of the truncus inferior. The lateral cord joins the anterior division of the truncus medialis to form the nervus medianus. Additionally, the $\mathrm{C} 5$ root and the nervus musculocutaneus are thin nerves compared with the normal thicknesses of the nerves. D) Right BP: The lateral cord originates only from the anterior division of the truncus superior. A branch of the anterior division of the truncus medius $\left.{ }^{* \star}\right)$ joins the nervus medianus as a third root. First, the branch joins the radix lateralis nervi mediani $\left(^{*}\right)$, then, this conjunction contributes to the median nerve with the radix medialis nervi mediani $(++)$. 
musculocutaneous nerve, while the others joined the radix lateralis nervi mediani, radix medialis nervi mediani and nervus medianus (Figure 3), In 3 of the 10 BPs, the division anterior of TM divided into two segments as the lateral and medial. The lateral branch combined with the radix lateralis nervi mediani, and the medial branch combined with the radix medialis nervi mediani, and then they formed the nervus medianus (Figures $3,4)$.

In 2 BPs (10\%), the nervus axillaris originated directly from the posterior division of the TS (Figure 2).
In one BP (5\%), the nervus cutaneous brachii medialis and nervus cutaneous antebrachii medialis originated from the T1 root as the main branch, and then divided (Figure 1).

The nervus subscapularis superior and inferior, and nervus thoracodorsalis originated from the posterior division of the TS in one BP $(5 \%)$. In the other BP $(5 \%)$, the nervus subscapularis superior and inferior also originated from the posterior division of the TS, while the nervus thoracodorsalis originated from the $\mathrm{PC}$. The nervus subscapularis superior arose from the PC as two branches in one BP (5\%). Although the normal sequence of these nerves originating from the PC (proximal to distal)

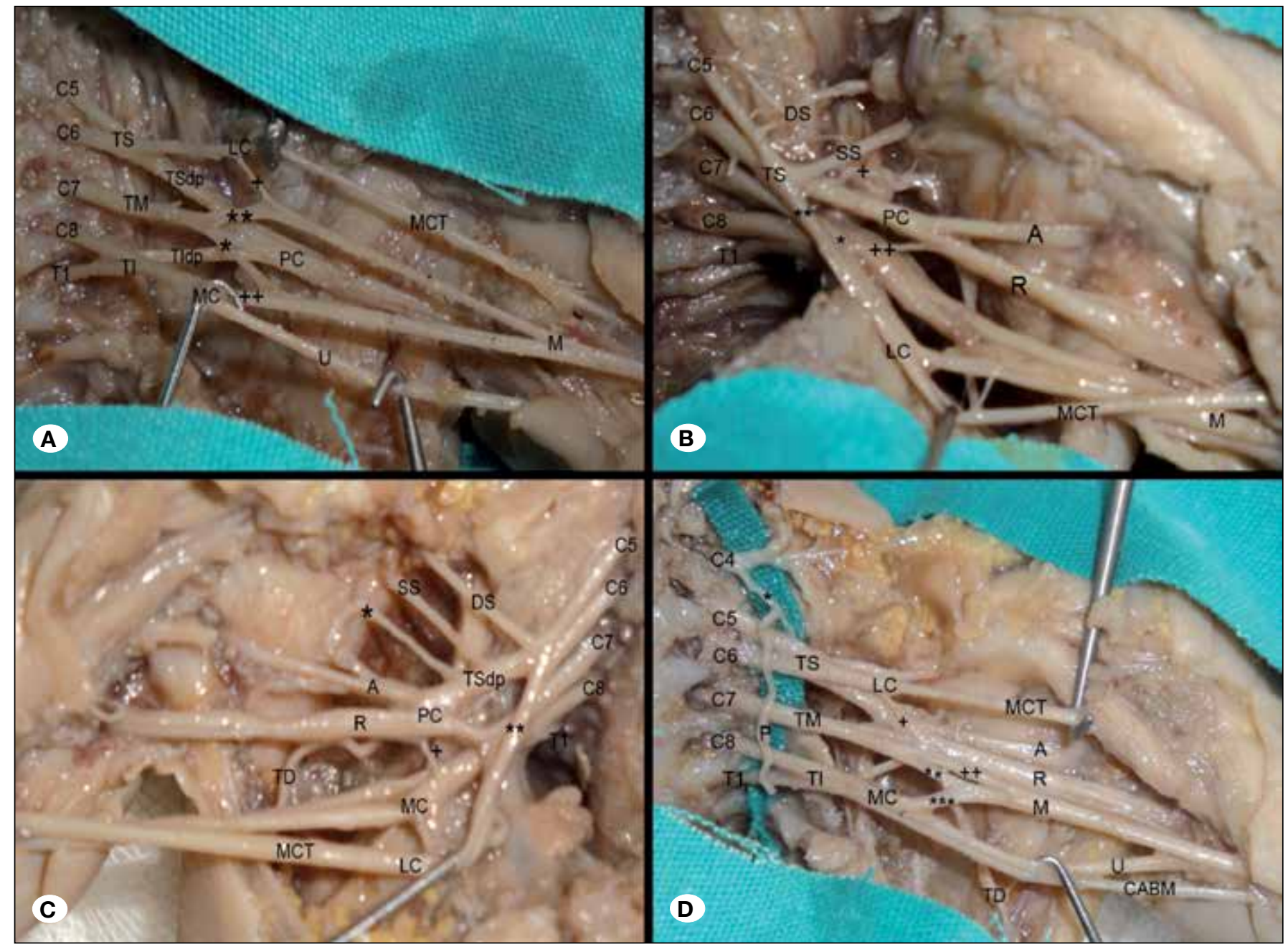

Figure 4: A) Left BP: the lateral cord originates only from the anterior division of the truncus superior. The anterior division of the truncus medius separates into two additional branches. The superior branch $\left(^{* *}\right)$ joins the radix lateralis nervi mediani $(+)$. The inferior branch $\left({ }^{*}\right)$ joins the radix medialis nervi mediani (++). The nervus medianus consists of the new radixes in the arm level. B) Left BP: the lateral cord and the anterior division of the truncus medius were removed with a tool. There is an additional thin connection (++) from the anterior division of the truncus medius $\left(^{*}\right)$ to the nervus radialis. The nervus suprascapularis originates from the anterior division of the truncus superior as two branches (SS and $\left.{ }^{\star}\right)$. $\left(^{* *}\right)$ : anterior division of the truncus superior. C) Right BP: the lateral cord and the anterior division of the truncus medius were removed with a tool. The nervus suprascapularis originates from the posterior division of the truncus superior as two branches (SS and *). There is an additional thin connection (+) from the medial cord to the nervus radialis $(+)$. $\left(^{* \star}\right)$ : anterior division of the truncus superior. D) Left BP: the lateral cord originates only from the anterior division of the truncus superior. The nervus medianus consist of four roots. The anterior division of the truncus medius separates into two branches, which are the superior branch (++) and inferior branch $\left(^{* *}\right)$. The radix lateralis nervi mediani $(+)$ joins the superior branch. The radix medialis nervi median $\left(^{* \star *}\right)$ joins the inferior brunch. Then, both conjunctions join each other and the nervus medianus is formed. 
Kirik A. et al: Fetal Brachial Plexus

is the nervus subscapularis superior, nervus thoracodorsalis, and then the nervus subscapularis inferior, they were arranged in the order of the nervus subscapularis superior, nervus subscapularis inferior and nervus thoracodorsalis in one BP (5\%).

The nervus thoracicus longus originated only from the roots C5 and C6 in 2 BPs (10\%) (Figure 3). There were 2 nervus thoracicus longus in one BP (5\%); one originated only from the $\mathrm{C} 5$ root and the other originated from the $\mathrm{C} 6$ and $\mathrm{C} 7$ roots (Figure 2).

In 13 BPs (65\%), the nervus dorsalis scapula originated at the output of the vertebral foramen and the width of the nerve was found to be similar to the branches given to the scalene muscles.

In $7 \mathrm{BPs}(35 \%)$, the nervus suprascapularis was found to originate proximal to the TS. In 4 BPs $(20 \%)$, it originated from the posterior division of the truncus superior (Figures 1, 2). There were 2 nervus suprascapularis in two BPs (10\%). In one BP, one of the nervus suprascapularis originated from the posterior division of the truncus superior (Figure 4), and the other originated from the anterior division (Figure 4). In the second BP, both nervus suprascapularis originated from the posterior division of the TS.

In $14 \mathrm{BPs}$, variation was detected in the nervus pectoralis lateralis. In 3 BPs (15\%), it originated from the anterior division of the TS, in $4 \mathrm{BPs}(20 \%)$, it originated from the anterior division of the TM (Figure 3) and in 7 (35\%) BPs, it originated from the anterior division of both the TS and the TM (Figures 2, 3).

In one BP $(5 \%)$, the nervus pectoralis medialis originated from the $\mathrm{C} 8$ root, in one BP (5\%) it originated from the T1 root (Figure 2) and in 5 BPs (25\%), it originated from the anterior division of the $\mathrm{Tl}$ (Figure 3).

\section{Measurement of Thickness}

In only one BP (5\%), the $\mathrm{C} 5$ nerve root that formed the truncus superior with only the $\mathrm{C} 6$ nerve root and without $\mathrm{C} 4$ nerve root involvement, was found to be thinner than normal. In the same $\mathrm{BP}$, the nervus musculocutaneous that takes some branches from $\mathrm{C} 5$ nerve root was also thin (Figure 3). The measurements of the nerve widths are shown in Table II. The elements of the plexus brachialis were arranged in the following order from large to small according to their average thicknesses: $\mathrm{C} 7>\mathrm{C} 6>\mathrm{C} 8>\mathrm{C} 5=\mathrm{T} 1 ; \mathrm{TS}>\mathrm{Tl}>\mathrm{TM} ; \mathrm{PC}>\mathrm{LC}>\mathrm{MC}$.

\section{DISCUSSION}

The normal anatomical structure of BP involves the last four cervical and the T1 spinal nerves. Sometimes, there can be contribution from both the C4 and T2 spinal nerves (20). In this study, it has been found that the BPs of the fetal cadavers were formed by the spinal nerves C4-T2. Kerr classified the prefixed brachial plexus anatomy in three groups with anatomic variations: if there is participation from $\mathrm{C} 4$ to $\mathrm{C} 5$, it is classified as Group $1(62.85 \%)$; if there is no participation from C4 to C5, it is classified as Group 2 (29.71\%); and after a portion of $\mathrm{C} 5$ joins $\mathrm{C} 4$ and unites the cervical plexus, this
Table II: Width of the Structures of Brachial Plexuses

\begin{tabular}{lcc}
\hline Parameters & Width of nerves $(\mathbf{m m})$ & Mean $(\mathbf{m m})$ \\
\hline C5 nerve root & $0.8-1.1$ & $1.0 \pm 0.103$ \\
\hline C6 nerve root & $1.1-1.4$ & $1.3 \pm 0.094$ \\
\hline C7 nerve root & $1.2-1.5$ & $1.4 \pm 0.107$ \\
\hline C8 nerve root & $0.9-1.2$ & $1.1 \pm 0.103$ \\
\hline T1 nerve root & $0.9-1.1$ & $1.0 \pm 0.071$ \\
\hline Superior trunk (TS) & $1.8-2.2$ & $2.1 \pm 0.117$ \\
\hline Medial trunk (TM) & $1.5-1.9$ & $1.7 \pm 0.141$ \\
\hline Inferior trunk (TI) & $1.7-2.2$ & $2.0 \pm 0.152$ \\
\hline Lateral cord (LC) & $1.7-2.1$ & $1.9 \pm 0.138$ \\
\hline Medial cord (MC) & $1.5-1.8$ & $1.6 \pm 0.097$ \\
\hline Posterior cord (PC) & $2.0-2.4$ & $2.3 \pm 0.112$ \\
\hline
\end{tabular}

group is classified as Group 3 (7.42\%) (9). In the present study, $50 \%$ of the BPs were found to be prefixed, while $15 \%$ of these prefixed BPs were also postfixed. In 10 cases, the BPs were found to have a normal anatomical structure that involved C5-C8 and T1. Kerr Group 3 was not detected in the present study. In a study conducted by Lee et al., a total of 152 BPs were analyzed in 77 adult cadavers and $77 \%$ were found to have normal structure (11). Prefixed BPs were found in $21.5 \%$ cases and, in only one case, both $\mathrm{C} 4$ and $\mathrm{T} 2$ were involved. According to the Kerr classification, Lee et al. found that $21.5 \%$ of their cases were Group 1, 77\% were Group 2 and no cases were in Group 3, which is similar to the results from the present study (11). In another study conducted by Uysal et al., $200 \mathrm{BP}$ were investigated and $25.5 \%$ of the cases were found to be in Kerr Group 1, 71.5\% had normal structure and 2.5\% had postfixed BPs. Kerr Group 3 was not detected in the study (24). A study conducted in Slovakia reported that $48 \%$ of the cases had prefixed BP and there was only one case of postfixed BP among 100 BPs (14). Another Brazilian study found that $24 \%$ of the cases were prefixed and $4 \%$ were postfixed among a total of 54 BPs (4). Finally, a study conducted in Korea reported $77 \%$ normal and $21.7 \%$ prefixed BPs among a total sample of 152 BPs (23).

Few studies have been conducted on fetal cadavers. Uzun and Bilgic evaluated 130 BPs from 65 infant cadavers and revealed that $69.23 \%$ of the cases had normal origin of $\mathrm{BP}$, while there was a variant connection between the C4 and C5 spinal nerves in $30.77 \%$ of the cases. Nonetheless, they found no contribution of the T2 spinal nerve (postfixed) (26). Kerr, Patterson and Scanion reported the presence of postfixed variation as $30 \%$ and $33 \%$ in their studies, respectively $(9,19)$. In different studies, a small number of postfixed BP has been reported and no cases were reported in the study by Uzun and Bilgic (26); however, in the present study, postfixed BPs were found in $15 \%$ of the cases $(4,14,26)$.

Another study performed by Uysal et al. on 200 BPs from fetal cadavers reported that $71.5 \%$ of the cases had normal 
anatomical structure of the BP. Prefixed BPs were observed in $25.5 \%$ of the cases and $2.5 \%$ of the cases were found to have postfixed BPs. They found one case in which the C4 and T2 nerves joined the formation. Also, in another case, the TI was formed by the ventral rami of the T1 and T2 nerves (24). In the present study, 3 BPs were found where both the C4 and T2 nerves joined the BP.

In another study conducted by Wozniak et al., spinal nerve root variations were detected in 35 plexuses. In 26 cases, the $\mathrm{C} 4$ nerve supernumerary root was found and in two cases the T2 nerve root formed the BP. Additionally, in four plexuses, the T1 nerve root was not observed (27).

The study by Kerr revealed that in $89 \%$ of the cases, the superior trunk was formed in the normal anatomical way and in $11 \%$ of the cases, variation was found (9). The study by Uysal et al. observed a variation at TS. It was formed by the ventral rami of the $\mathrm{C} 4$ and $\mathrm{C} 5$ nerves in $1 \%$ of cases while in one plexus (24). The study by Nayak et al. described a superior trunk variation that had been formed by the $\mathrm{C} 5, \mathrm{C} 6$ and $\mathrm{C} 7$ nerve roots (17). Different authors also found this variation $(2,13)$. Furthermore, the study by Aragão et al. reported that there was a formation of four trunks in $2.5 \%$ of the cases (2). In the present study, 10 cases were observed in which the C4, C5, C6 roots formed the TS, while in the remaining $50 \%$ of the BPs, the $\mathrm{C} 5$ and $\mathrm{C} 6$ roots formed the TS.

C7 nerve roots formed all TMs in the present study, similar to Kerr's study (9). No variations were observed in the TM, although the study by Kerr reported that there was a variation of the TM in $6.1 \%$ of the cases (9).

The Kerr study determined that the joining of the $\mathrm{C} 8$ and $\mathrm{T} 1$ formed the inferior trunk in $95 \%$ of the cases, and $5 \%$ of the cases had variation (9). In 17 BPs ( $85 \%)$, the C8 and T1 roots formed the truncus inferior (TI), while in $3(15 \%)$ BPs, the C8, $\mathrm{T} 1$ and $\mathrm{T} 2$ roots formed the TI in the present study.

The Kerr study also revealed that no lateral cord was formed in $4 \%$ of cases and the MC was formed in all cases. In $36 \mathrm{BPs}$ (20.57\%), he was unable to find the real PC unless a single nerve, the nervus radialis, was considered to represent the PC (9). The study by Uysal et al. revealed variations in the LC and MC. The LC consisted of only the anterior division of the TS $(2.5 \%)$, a branch of the anterior division of the TM joined the MC $(5 \%)$, a branch of the anterior division of the TM contributed to the LC, and another branch of the anterior division of the TM contributed to the nervus ulnaris $(0.5 \%)$ (24). In the present study, LCs were formed by only the TS in $7 \mathrm{BPs}(35 \%)$. In one of the BCs (5\%), the anterior division of the TM gave off a small branch to the LC. In one BP (5\%), the posterior divisions of the TM and Tl first formed the PC, and the posterior division of the TS joined the PC after giving the nervus subscapularis superior and inferior. In the other BP (5\%), the posterior division of the TS first gave off the nervus thoracodorsalis, and then formed the PC with the posterior divisions of the TM and TI.
The nervus medianus variants constitute the majority of the anatomical studies of the terminal branches of the plexus brachialis $(15,16)$. The most common variation of the nervus medianus has been reported as the formation from three roots $(21,22)$, similar to the present study (50\% of BPs).

The study by Fuss revealed that in $158 \mathrm{BPs}$, the fibers of the nervus ulnaris originated either from the $\mathrm{MC}$ or also from the LC. Lateral root involvement was observed in $56 \%$ of cases, which suggested that this should be considered normal and not a variation (5). No anatomical variations and a contribution of the lateral root to the nervus ulnaris were observed in the present study.

In another study conducted by Wozniak et al., distal nerve variations were observed in 35 cases (15.90\%)(27). Uysal et al. reported terminal branch variations in $8.5 \%$ of the cases they observed where the roots of the nervus medianus joined in the distal part of the arm; in $2.5 \%$ of the cases, the axillary nerve was separate from the posterior division of the TS. They also reported a connection in $1 \%$ of the cases between the nervus medianus and nervus musculocutaneous (24). In the present study, variations were also observed in the nervus axillaris (10\%), nervus radialis $(5 \%)$, nervus cutaneous brachii medialis and nervus cutaneous antebrachii medialis $(5 \%)$, nervus thoracicus longus (10\%), nervus suprascapularis $(35 \%)$, nervus pectoralis lateralis $(70 \%)$ and nervus pectoralis medialis (35\%) in the $20 \mathrm{BPs}$

The study by Kerr revealed that the fibers of the anterior segments of the spinal nerves were counted by microdissection and the thicknesses were determined as $\mathrm{C} 7>\mathrm{C} 6>\mathrm{C} 8>\mathrm{C} 5=\mathrm{T} 1$, according to the number of fibers (9). The study by Uysal et al. reported morphometric measurements of the fetuses. It was determined that $\mathrm{C} 5$ and $\mathrm{T} 1$ were equal and thin, while $\mathrm{C} 7$ and C8 were equal and thick in measurements made at the 3rd trimester. The TM was found to be thinner than the other trunks. The PC was the thickest cord, and the nervus radialis was identified as the thickest terminal branch (24). The study by Uzun and Bilgic revealed the thickness of the plexus brachialis components as $\mathrm{C} 7>\mathrm{C} 6>\mathrm{C} 8>\mathrm{C} 5=\mathrm{T} 1, \mathrm{TS}=\mathrm{Tl}>\mathrm{TM}$, $P C>L C>M C$ (26). Since the fetuses were not at the same month, were of different sizes and the development of the fetuses was not completed, it was thought that the lengths and thicknesses of the nerves would not be statistically meaningful. However, the plexus brachialis elements were arranged in the following order from large to small according to their average thicknesses: $\mathrm{C} 7>\mathrm{C} 6>\mathrm{C} 8>\mathrm{C} 5=\mathrm{T} 1$; $\mathrm{TS}>\mathrm{Tl}>\mathrm{TM}$; $\mathrm{PC}>\mathrm{LC}>\mathrm{MC}$.

\section{- CONCLUSION}

The plexus brachialis is an important formation due to its complex structure, its relation to other structures, and its anatomical region. This anatomic structure of the plexus must be comprehensively understood by surgeons engaged in brachial plexus surgery. 


\section{REFERENCES}

1. Akboru IM, Solmaz I, Secer HI, Izci Y, Daneyemez M: The surgical anatomy of the brachial plexus. Turk Neurosurg 20: 142-150, 2010

2. Aragão JA, Melo LO, Barreto ATF, Da Silva Leal AT, Reis FP: Variations in the formation of the trunks of brachial plexus. $J$ Morphol Sci 31:48-50, 2014

3. Dunkerton MC, Boome RS: Stab wounds involving the brachial plexus. J Bone Joint Surg 70-B: 566-570, 1988

4. Fazan VPS, Amadeu AS, Caleffi AL, Filho OAR: Brachial plexus variations in its formation and main branches. Acta Cir Bras 18 Supl 5:14-18, 2003

5. Fuss FK: The lateral root of the ulnar nerve. Acta Anat (Basel) 134:199-205, 1989

6. Gacek RR: Neck dissection injury of a brachial plexus anatomical variant. Arch Otolaryngol Head Neck Surg 116: 356-358, 1990

7. Guday E, Bekele A, Muche A: Anatomical study of prefixed versus postfixed brachial plexuses in adult human cadaver. ANZ J Surg 87:399-403, 2017

8. Hentz VR, Meyer RD: Brachial plexus microsurgery in children. Microsurgery 12:175-185, 1991

9. Kerr AT: The brachial plexus of nerves in man, the variations in its formation and branches. Am J Anat 23:285-392, 1918

10. Laurent JP, Lee R, Shenaq S, Parke JT, Solis IS, Kowalik L: Neurosurgical correction of upper brachial plexus birth injuries. J Neurosurg 179:197-203, 1993

11. Lee HY, Chung IH, Sir WS, Kang HS, Lee HS, Ko JS, Lee MS, Pork SS: Variation of the ventral rami of the brachial plexus. J Korean Med Sci 7:19-24, 1992

12. MacCarty CS: Surgical exposure of the brachial plexus. Surg Neurol 21:593-596, 1984

13. Matejcik V: Aberrant formation and clinical picture of brachial plexus from the point of view of a neurosurgeon. Bratisl Lek Listy 104:291-299, 2003

14. Matejcik V: Variations of nerve roots of the brachial plexus. Bratisl Lek Listy 106:34-36, 2005
15. Nakatani T, Tanaka S: Absence of the musculocutaneous nerve with innervation of coracobrachialis, biceps brachii, brachialis and the lateral border of the forearm by branches from the lateral cord of the brachial plexus. J Anat 16:459460, 1997

16. Nakatani T, Tanaka S, Mizukami S: Bilateral location of the axillar artery posterior to the medial cord of the brachial plexus. J Anat 16:457-459, 1996

17. Nayak S, Somayaji N, Vollala VR, Reghunthan D, Rodrigues V: $A$ rare variation in the formation of upper trunk of the brachial plexus: A case report. Neuroanatomy 4:37, 38, 2005

18. Ochiai $N$, Nagano A, Sugioka $H$, Hara T: Nerve grafting in brachial plexus injuries. J Bone Joint Surg 78-B:754-758, 1996

19. Patterson KW, Scanlon P: An unusual complication of brachial plexus sheath cannulation. Br J Anaesth 65:542-543, 1990

20. Richard LD, Wayne V, Adam WM: Gray's test book of anatomy for student. Elsevier Churchill Livingstone, 2005:661- 663

21. Sargon M, Uslu SS, Celik HH, Aksit D: A variation of the median nerve of the level of brachial plexus in man. Bull Assoc Anat (Nancy) 79:25, 26, 1995

22. Sarsilmaz M, Sendemir E, Celik H, Gumusalan Y, Simsek C: Some variations of the brachial plexus in man. Turk J Med Res 2:161-165, 1993

23. Singhal S, Rao VV, Ravindranath R: Variations in brachial plexus and the relationship of median nerve with the axillary artery: A case report. J Brachial Plex Peripher Nerve Inj 2:21, 2007

24. Uysal II, Seker M, Karabulut AK, Buyukmumcu M, Ziylan T: Brachial plexus variations in human fetuses. Neurosurgery 53 : 676-684, 2003

25. Uzmansel D, Kurtoglu Z, Kara A, Ozturk NC: Frequency, anatomical properties and innervation of axillary arch and its relation to the brachial plexus in human fetuses. Surg Radiol Anat 32(9):859-863, 2010

26. Uzun A, Bilgic S: Some variations in the formation of the brachial plexus in infants. Turk J Med Sci 29:573-577, 1999

27. Wozniak J, Kędzia A, Dudek K: Brachial plexus variations during the fetal period. Anat Sci Int 87:223-233, 2012 